\author{
Thomas G. Smith \\ Nick P. Talbot \\ Keith L. Dorrington \\ Peter A. Robbins
}

\section{Intravenous iron and pulmonary hypertension in intensive care}

Accepted: 22 June 2011

Published online: 2 August 2011

(C) Copyright jointly held by Springer and ESICM 2011

\section{Dear Editor,}

We read with interest the case reported by Weber-Carstens et al. [1] of a woman with longstanding idiopathic pulmonary arterial hypertension who presented with severe polytrauma. Her admission was complicated by critical hypoxia and severe acute-onchronic pulmonary hypertension resulting in acute right heart decompensation. During this life-threatening phase, the authors report that the benefits of standard combination therapy in reducing right ventricular afterload were short-lived in the face of worsening hypoxia. Recent work from our group and others has introduced the possibility that intravenous iron may provide additional benefit in this setting.

In healthy iron-replete men studied over 1 week at high altitude (equivalent to sea level $\mathrm{FiO}_{2} \sim 0.12$ ) we found that established hypoxiainduced pulmonary hypertension was significantly reversed by a single $200 \mathrm{mg}$ dose of intravenous iron sucrose [2]. This effect was evident within $4 \mathrm{~h}$ of infusion-rapid enough to be of possible benefit in offloading the right ventricle in the acute clinical setting. We also studied patients with chronic mountain sickness over 1 month at high altitude and found that depletion of iron by venesection was associated with worsening pulmonary hypertension despite a large reduction in haematocrit (although this effect was not immediately reversed by subsequent iron infusions) [2].

This work was preceded by an 8-h laboratory study of healthy ironreplete volunteers in which the increase in pulmonary arterial pressure caused by hypoxia was blunted by prior intravenous infusion of iron sucrose $(200 \mathrm{mg})$, while the pulmonary vascular response to hypoxia was enhanced by reduction of iron availability with desferrioxamine [3]. The dose of iron used in these studies is small relative to total body iron stores (approximately $4 \mathrm{~g}$ ), and current intravenous formulations such as iron sucrose are very safe.

These studies indicate that hypoxic pulmonary hypertension can be attenuated by increasing iron availability and exacerbated by decreasing iron availability. This interaction between iron, hypoxia and the pulmonary circulation is consistent with known effects of iron on the hypoxiainducible factor (HIF) family of transcription factors and involvement of HIF in regulating cardiopulmonary physiology [2-4]. Studies from several centres have subsequently confirmed a link between iron status and idiopathic pulmonary arterial hypertension, demonstrating that iron deficiency is unexpectedly common in this disease and independently worsens morbidity and mortality (recently reviewed by Rhodes et al. [5]). Two European studies investigating the use of intravenous iron in pulmonary arterial hypertension are now underway [5].

We look forward to the results of these and other studies. In the meantime, the available evidence raises the possibility that intravenous iron may be beneficial as a rescue therapy when hypoxia and pulmonary hypertension are acutely life-threatening and conventional treatment is inadequate.

\section{References}

1. Weber-Carstens S, Lojewski C, Bercker S, Schaser KD, Fateh-Moghadam S, Kaisers U (2011) Acute right heart decompensation in a multiple trauma patient with chronic pulmonary hypertension. Intensive Care Med 37:723-724

2. Smith TG, Talbot NP, Privat C, Rivera-Ch M, Nickol AH, Ratcliffe PJ, Dorrington KL, Leon-Velarde F, Robbins PA (2009) Effects of iron supplementation and depletion on hypoxic pulmonary hypertension: two randomized controlled trials. JAMA 302:1444-1450

3. Smith TG, Balanos GM, Croft QP, Talbot NP, Dorrington KL, Ratcliffe PJ, Robbins PA (2008) The increase in pulmonary arterial pressure caused by hypoxia depends on iron status. J Physiol 586:5999-6005

4. Smith TG, Robbins PA, Ratcliffe PJ (2008) The human side of hypoxiainducible factor. Br J Haematol 141:325-334

5. Rhodes CJ, Wharton J, Howard L, Gibbs JS, Vonk-Noordegraaf A, Wilkins MR (2011) Iron deficiency in pulmonary arterial hypertension: a potential therapeutic target. Eur Respir J. doi: 10.1183/09031936.00037711

T. G. Smith $(\bowtie) \cdot$ N. P. Talbot •

K. L. Dorrington · P. A. Robbins

Department of Physiology,

Anatomy and Genetics,

University of Oxford, Parks Road,

Oxford OX1 3PT, UK

e-mail: thomas.smith@dpag.ox.ac.uk

Tel.: +44-1865-272487

Fax: +44-1865-282486

\section{T. G. Smith - K. L. Dorrington}

Nuffield Department of Anaesthetics, John Radcliffe Hospital, Headley Way, Oxford OX3 9DU, UK

\section{N. P. Talbot}

Oxford Centre for Respiratory Medicine, Churchill Hospital, Old Road,

Oxford OX3 7LJ, UK 